\title{
Factors Influencing Childhood Immunization in Uganda
}

\author{
Edward Bbaale \\ Centre for Global Development, Washington, D.C. and Makerere University-Kampala, Uganda
}

\begin{abstract}
This paper investigates the factors associated with childhood immunization in Uganda. We used nationallyrepresentative data from Uganda Demographic and Health Survey (UDHS) of 2006. Both bivariate and multivariate approaches were employed in the analysis. The bivariate approach involved generating average percentages of children who were immunized, with analysis of pertinent background characteristics. The multivariate approach involved employing maximum likelihood probit technique and generating marginal effects to ascertain the probability of being immunized, given the same background characteristics. It revealed that slightly over $50 \%$ of children in Uganda were fully immunized. Additionally, $89 \%, 24 \%$, $52 \%$, and $64 \%$ received BCG, DPT, polio and measles vaccines respectively. Factors which have a significant association with childhood immunization are: maternal education (especially at post-secondary level), exposure to media, maternal healthcare utilization, maternal age, occupation type, immunization plan, and regional and local peculiarities. Children whose mothers had post-secondary education were twice as likely to be fully immunized compared to their counterparts whose mothers had only primary education $(p<0.01)$. Thus, gender parity in education enhancement efforts is crucial. There is also a need to increase media penetration, maternal healthcare utilization, and to ensure parity across localities and regions.
\end{abstract}

Key words: BCG vaccine; DPT vaccine; Polio vaccine; Full immunization; Measles vaccine; Uganda

\section{INTRODUCTION}

Immunization is a proven tool for controlling and eliminating life-threatening infectious diseases and is estimated to avert 2 to 3 million deaths each year. It is one of the most cost-effective health investments, with proven strategies that make it accessible to even the most hard-to-reach and vulnerable populations (1). Universal immunization of children against eight vaccine-preventable diseases [tuberculosis, diphtheria, whooping cough (pertussis), tetanus, hepatitis B, respiratory diseases caused by Haemophilus influenzae, polio, and measles] is crucial to reducing infant and child mortality $(2,3,4,5,6,7)$. Indeed, immunization is a major health intervention for child survival throughout the world (8). Consequently, childhood immunization remains a key channel for the attainment of the Millennium Development Goal 4 (MDG 4) of reducing child mortality by two-thirds within 2015.

Thus, it is no wonder that WHO launched the Expanded Programme on Immunization (EPI) in

Correspondence and reprint requests:

Centre for Global Development

Washington, D.C. and Makerere University-

Kampala, Uganda

Email: edward_bbaale@yahoo.com
1974, and many developing countries adopted it. Despite this effort, over 24,000 children die of vaccine-preventable diseases every day around the world. This is equivalent to 1 child dying every 3.6 seconds, 16-17 children dying every minute, and just about 9 million children dying every year. Of these deaths in 2008, a bigger proportion occurred in sub-Saharan Africa (4.4 million) and South Asia (2.8 million) compared to Latin America, the Caribbean ( 0.2 million), and industrialized countries ( 0.1 million). The Government of Uganda is committed to achieving the targets set out in the recentlylaunched National Development Plan (NDP, 20102015), many of which are in line with the MDGs to be achieved by 2015. In spite of these efforts, huge challenges still remain. The under-five and infant mortality rates are still high at 137 and 78 per 1,000 livebirths respectively (9). In addition, Uganda's total fertility rate (TFR) of about 7 children per woman is one of the highest in the world (2). It is noteworthy that any efforts to reduce the total fertility rate will yield very little, if not matched with tremendous reductions in the infant mortality rate.

Therefore, it is clear that, despite the universal childhood immunization programme, especially in developing countries, like Uganda, poor child health still persists. This has aroused a lot of inter- 
est among government policy-makers and other stakeholders (especially donors) in understanding the factors influencing the use of childhood immunization services. A key issue of interest is whether the children are fully immunized against all vaccine-preventable diseases and the set of associated factors that may need policy intervention. This paper contributes to the body of knowledge on the factors influencing the attainment of a full immunization package by providing answers to the following questions: (i) controlling for other socioeconomic characteristics, does the level of education acquired by a woman affect her decision in terms of seeking full immunization for her child?, (ii) if so, which level of a woman's schooling has a significant impact on this decision?, and (iii) do other socioeconomic and environmental factors matter?

There is a growing body of literature exposing the factors associated with childhood immunization. Different authors have put forward various factors believed to be associated with parental healthcareseeking behaviour toward their children. The most frequently-cited factor influencing childhood immunization is maternal education. A noteworthy strand of literature exposes the pathways through which maternal education influences healthcareseeking behaviour $(10,11,12,13)$. It is argued that maternal education is accompanied with: changes in attitudes/beliefs and practices, autonomy and decision-making, control over resources, accessibility to a well-paying job and educated spouses, and control over their fertility behaviour, all of which enhance healthcare-seeking. Furthermore, a number of authors expose maternal education as an important factor influencing childhood immunization $(3,4,8,10,14,15,16,17,18,19,20,21)$. Other important factors found in the literature are education of the spouse (3), household wealth status $(3,5,16,22,23)$ and distance to healthcare facilities $(4,5,24,25,26,27,28)$, along with locational and regional differences $(3,4,14,19)$, age-cohort of the mother $(6,8)$, the use of antenatal care $(8,20,29)$, immunization plan (16), birth order (19), occupation of parents (3), and gender of the child (8). The literature survey informed us of our choice of the variables included in the analysis. In addition, it has exposed the fact that no nationally-representative study had so far been undertaken in Uganda. The study by Nankabirwa et al. (21) focused on eastern part of the country and children of less than 6 months who are not fully immunized. Therefore, our study, using nationally-representative data and focusing on fully-immunized children, represents a real scenario.

\section{MATERIALS AND METHODS}

We obtained approval from Macro International to use the data from Uganda Demographic and Health Survey (UDHS) of 2006. It is a nationallyrepresentative survey of 8,531 women aged 15-49 years and 2,503 men aged 15-54 years. The survey collected information on vaccination coverage for 25,020 children aged 0-36 months born in the five years preceding the survey. Of them, 16,131 (64.5\%) were aged 0-11 months, 7,623 (30.5\%) were aged 12-23 months, and 1,266 (5\%) were aged 24-36 months. To analyze the probability of being fully immunized, we considered children of 12-36 months since they are believed to have completed the immunization cycle. To analyze the probability of receiving the individual vaccines, we considered even the younger children; hence, we used the entire sample from the age-cohort of 0-36 months. The UDHS report also considered this cohort during their descriptive analysis (2). Information on vaccination coverage was collected in two ways in the UDHS: from vaccination cards shown to the interviewer and from mothers' verbal reports. If the cards were available, the interviewer copied the vaccination dates directly onto the questionnaire. Of 7,581 children, 626 (8\%) did not have cards, 3,965 $(52 \%)$ had cards and were seen by the interviewer, $2,122(28 \%)$ had cards but were not seen by the interviewer, and 868 (12\%) no longer had their cards (missing). When there was no vaccination card for the child or if a vaccine had not been recorded on the card as being given, the respondent was asked to recall the vaccines given to her child (2). Therefore, this was a crude immunization coverage which does not accurately show children properly immunized or actually protected against disease.

For the survey, three sets of questionnaire were used, namely; household questionnaire, women's questionnaire, and men's questionnaire. Sampling was done in two stages-in the first stage, 321 clusters were selected from among a list of clusters sampled in the 2005-2006 Uganda National Household Survey (UNHS) to generate matching samples that can allow for linking of the 2006 UDHS health indicators to poverty data from the 2005-2006 UNHS. Additional 17 clusters were selected from the 2002 Census from Karamoja to increase the sample-size to allow for reporting of the Karamoja-specific estimates in the UDHS. Finally, 30 internally-displaced camps (IDCs) were selected from a list of camps compiled by the United Nations Office for Coordination of Human Affairs, completing a total of 368 primary sampling units (2). In the second stage, 
households in each cluster were selected based on a complete listing of households as per UNHS listing. However, in addition to the UNHS-sampled households, another 20 households were randomly selected in each cluster (2). Uganda Bureau of Statistics (UBOS) recruited and trained staff to serve as supervisors, field editors, male and female interviewers, field coordinators, and health technicians. The UBOS, Macro International and invited experts from government ministries led the four-week training that included lectures, presentations, practical demonstrations, and practice interviewing in small groups as well as two days of field practice (2).

Our dependent variables were constructed as follows: (a) fully immunized: equals 1 if a child received the eight dozes against vaccine-preventable diseases and zero otherwise, (b) BCG: 1 if a child received BCG and zero otherwise, (c) DPT: 1 if a child received the three doses of DPT and zero otherwise; (d) Polio: 1 if a child received the three doses of polio vaccine and zero otherwise, and (e) Measles: 1 if a child was immunized against measles and zero otherwise.

We controlled for a number of independent variables guided by the previous literature. Maternal education was categorized into four outcomes as follows: $0=$ no education, $1=$ primary education, $2=$ secondary education, and $3=$ post-secondary education (tertiary and university). In all our regressions, no education was the reference category. Educational attainment of men was categorized in the same way. As shown in Table 1, age of the mother was broken into five-year age-cohorts as: 15-19, $>19-24,>24-29$, >29-34, >34-39, >39-44, >44-49. In all our regressions, 15-19 age-cohort was used as the reference category. Location was defined as equal to 1 if a mother was in the urban area and zero otherwise. Nine region dummies were defined as $1=$ Central 1, 2=Central 2, 3=Kampala, 4=East Central, 5=Eastern, $6=$ North, $7=$ West Nile, $8=$ Western, and $9=$ Southwest. The Central 1 was the reference category. We defined three religious dummies as $1=$ Catholics, $2=$ Protestants, $3=$ Muslims, and $4=$ Others. The category 'Others' included Evangelicals (born-again Christians), Seventh Day Adventists, Orthodox, and Traditionalists/Non-believers. Catholics were used as the reference category. The wealth index is provided in the dataset in terms of quintiles; $1=$ Poorest, $2=$ Poor, $3=$ Middle, $4=$ Rich, $5=$ Richest. The poorest quintile was used as the reference category. Occupation of the mother and spouse was categorized as follows: $1=$ White-collar job, 2=Services/sales, 3=Agriculture, 4=Blue-collar

\begin{tabular}{|c|c|c|}
\hline & & \\
\hline Characteristics & Number & Percentage \\
\hline $\begin{array}{l}\text { Woman's education: No } \\
\text { education (ref.) }\end{array}$ & 9,470 & 32 \\
\hline Primary & 17,463 & 58 \\
\hline Secondary & 2,632 & 9 \\
\hline Post-secondary & 525 & 2 \\
\hline \multicolumn{3}{|l|}{ Partner's education: No } \\
\hline Primary & 17,648 & 62 \\
\hline Secondary & 5,349 & 19 \\
\hline Post-secondary & 1,695 & 6 \\
\hline Location: Urban (ref.) & 3,166 & 11 \\
\hline Rural & 26,924 & 90 \\
\hline Region: Central 1 (ref.) & 2,670 & 9 \\
\hline Central 2 & 3,059 & 10 \\
\hline Kampala & 1,506 & 5 \\
\hline East Central & 3,657 & 12 \\
\hline Eastern & 3,551 & 12 \\
\hline North & 6,502 & 22 \\
\hline West Nile & 2,411 & 8 \\
\hline Western & 3,450 & 12 \\
\hline Southwest & 3,284 & 11 \\
\hline \multicolumn{3}{|l|}{ Age-cohort: $15-19$ years } \\
\hline$>19-24$ & 2,790 & 9 \\
\hline$>24-29$ & 4,918 & 16 \\
\hline$>29-34$ & 6,296 & 21 \\
\hline$>34-39$ & 5,980 & 20 \\
\hline$>39-44$ & 5,027 & 17 \\
\hline$>44-49$ & 4,643 & 15 \\
\hline \multicolumn{3}{|l|}{ Wealth quintiles: Poorest } \\
\hline Poor & 6,090 & 20 \\
\hline Middle & 5,882 & 20 \\
\hline Rich & 5,722 & 19 \\
\hline Richest & 5,018 & 17 \\
\hline \multicolumn{3}{|l|}{ Woman's occupation: } \\
\hline White-collar job (ref.) & 673 & 2 \\
\hline Services/sales & 3,253 & 12 \\
\hline Agriculture & 22,719 & 80 \\
\hline Blue-collar job & 1,711 & 6 \\
\hline \multicolumn{3}{|l|}{ Partner's occupation: } \\
\hline White-collar job (ref.) & 2,430 & 8 \\
\hline Services/sales & 3,750 & 13 \\
\hline Agriculture & 18,638 & 63 \\
\hline Blue-collar job & 4,642 & 16 \\
\hline $\begin{array}{l}\text { Children's mmunization } \\
\text { card: No card (ref.) }\end{array}$ & 626 & 8 \\
\hline Card available and seen & 3,965 & 52 \\
\hline Card not seen & 2,122 & 28 \\
\hline $\begin{array}{l}\text { No longer have the } \\
\text { card (missing) }\end{array}$ & 868 & 12 \\
\hline Source: author's computa & ns from & DHS 2006 \\
\hline
\end{tabular}


job. The white-collar workers were used as the reference category. Exposure to media was categorized as follows: $1=$ Not at all, $2=$ Less than once a week, $3=$ At least once a week, 4=Every day. Those who had no exposure to media at all were used as the reference category.

During the analysis, we employed both bivariate and multivariate approaches. The bivariate approach involved generating average percentages of children who were vaccinated, with background characteristics. Under the multivariate approach, maximum likelihood probit technique was used. After a probit estimation, we generated marginal effects to interpret the results as probabilities of being vaccinated, given the background characteristics.

\section{RESULTS}

Results are presented from both bivariate and multivariate analyses. Our results are generated using sample weights and, hence, these are nationally representative. Table 2 shows the bivariate analysis. It reveals that, on average, $54 \%$ of children in Uganda were fully immunized, 89\% received a full dose of BCG, 24\% received DPT, 52\% received polio, and $64 \%$ received the measles vaccine. The percentage of immunized children increased with maternal education; $63 \%$ of children whose mothers had post-secondary education were immunized compared to $53 \%$ of children having mothers with no education. Looking at the individual vaccines, the positive impact of maternal education is very clear. The findings of multivariate analysis in Table 3 confirm the bivariate results. Children whose mothers had at least primary education increased the probability of being fully immunized by $8-14 \%$ $(p<0.05)$ compared to the counterparts with no education. Children whose mothers had at least secondary education were $6-7 \%(\mathrm{p}<0.05)$ more likely to receive the three doses of DPT and polio vaccines compared to the counterparts having mothers with no education. Children whose mothers had at least primary education were $7-11 \%(\mathrm{p}<0.01)$ more likely to be vaccinated against polio compared to the counterparts having mothers with no education.

Education of partner of the mother also portrayed the same picture as that of maternal education for full immunization and also for individual vaccines (Table 2). However, partner's education is statistically insignificant in the multivariate analysis and, hence, the coefficients have not been reported in Table 3 . The wealth status of the household is marginally significant in the regression analysis for polio and measles vaccines. Children from the richest wealth quintile increased the probability of being vaccinated against polio and measles by $7 \%(\mathrm{p}<0.1)$ compared to the counterparts in the poorest quintile (Table 3). Considering the bivariate findings, $53 \%$ and $67 \%$ of children in the richest quintile received polio and measles vaccines compared to $48 \%$ and $65 \%$ of the counterparts in the poorest quintile respectively.

The findings also reveal interesting locational and regional differences; $58 \%$ of children in urban areas were fully immunized compared to $53 \%$ of children in rural areas. A similar pattern is observed by looking into the individual vaccines (Table 2 ). Of the 9 regions, the North and West Nile had the highest percentage of children fully immunized and those who received BCG (59\% and 93\% respectively) while the lowest percentage was $40 \%$ and $75 \%$ for Central 1 respectively. The North had the highest percentage of children (32\%) who received the three doses of DPT while the lowest percentage was $12 \%$ for Central 1 . Western and Southwest had the highest percentage of children (58\%) who received the three doses of polio while the lowest percentage was $44 \%$ for Central 1 . The North had the highest percentage of children immunized against measles (71\%) while the lowest percentage was $54 \%$ for Central 1 (Table 2). These differences were also confirmed in the multivariate analysis where we undertook joint significance tests for the regional dummies in our regressions. It revealed that our regional dummies are jointly significant in all our regressions ( $p r o b>\mathrm{chi}^{2}=0.0000$ for all) (Table 3).

There are also differences owing to religious affiliation. Children from Muslim families reduced the probability of receiving the 3 doses of DPT by 3\% $(\mathrm{p}<0.05)$ compared to the counterparts from Catholic families (Table 3). Children belonging to 'Other' religions increased the probability of being vaccinated against polio by 7-9\% $(\mathrm{p}<0.05)$ compared to the counterparts belonging to Catholic religion (Table 3). Considering the bivariate analysis in Table 2, a high percentage of Catholic children were fully immunized (56\%) compared to the rest, with the worst performer being Protestants (51\%) (Table 2). A similar pattern was observed for individual vaccines apart from polio vaccine where children belonging to 'Other' religions had the highest percentage $(58 \%)$ of children vaccinated against polio compared to the rest (Table 2).

The importance of prenatal care is reflected in our findings; $48 \%$ of children whose mothers sought 


\begin{tabular}{|c|c|c|c|c|c|c|}
\hline Characteristics & $\begin{array}{c}\text { No. of } \\
\text { children }\end{array}$ & $\begin{array}{c}\text { Fully- } \\
\text { immunized (\%) }\end{array}$ & $\begin{array}{l}\text { BCG } \\
(\%)\end{array}$ & $\begin{array}{l}\text { DPT } \\
(\%)\end{array}$ & $\begin{array}{c}\text { Polio } \\
(\%)\end{array}$ & $\begin{array}{l}\text { Measles } \\
(\%)\end{array}$ \\
\hline Woman's education: No education (ref.) & 1,824 & 53 & 88 & 28 & 48 & 64 \\
\hline Primary & 4,686 & 53 & 88 & 22 & 52 & 63 \\
\hline Secondary & 896 & 58 & 90 & 26 & 54 & 67 \\
\hline Post-secondary & 185 & 63 & 97 & 30 & 63 & 71 \\
\hline Partner's Education: No education (ref.) & 799 & 52 & 88 & 28 & 44 & 64 \\
\hline Primary & 4,349 & 52 & 88 & 22 & 52 & 63 \\
\hline Secondary & 1,527 & 56 & 90 & 27 & 53 & 66 \\
\hline Post-secondary & 458 & 62 & 95 & 28 & 57 & 73 \\
\hline Location: Urban (ref.) & 847 & 58 & 92 & 30 & 51 & 68 \\
\hline Rural & 6,744 & 53 & 88 & 24 & 52 & 64 \\
\hline Region: Central 1 (ref.) & 663 & 40 & 75 & 12 & 44 & 54 \\
\hline Central 2 & 645 & 51 & 83 & 20 & 55 & 62 \\
\hline Kampala & 454 & 57 & 91 & 30 & 51 & 66 \\
\hline East Central & 920 & 49 & 88 & 23 & 46 & 57 \\
\hline Eastern & 971 & 50 & 90 & 24 & 53 & 61 \\
\hline North & 1,647 & 59 & 93 & 32 & 50 & 71 \\
\hline West Nile & 625 & 59 & 93 & 26 & 52 & 66 \\
\hline Western & 862 & 58 & 92 & 24 & 58 & 69 \\
\hline Southwest & 804 & 55 & 82 & 21 & 58 & 64 \\
\hline Religion: Catholic (ref.) & 3,484 & 56 & 90 & 28 & 51 & 66 \\
\hline Protestant & 2,500 & 51 & 88 & 21 & 53 & 64 \\
\hline Muslim & 862 & 52 & 86 & 21 & 48 & 61 \\
\hline Other & 486 & 54 & 88 & 24 & 58 & 61 \\
\hline Wealth quintiles: Poorest (ref.) & 1,906 & 55 & 91 & 29 & 48 & 65 \\
\hline Poor 1 & 1,645 & 53 & 88 & 24 & 51 & 63 \\
\hline Middle & 1,423 & 52 & 86 & 21 & 54 & 61 \\
\hline Rich & 1,355 & 52 & 87 & 20 & 54 & 64 \\
\hline Richest & 1,262 & 57 & 90 & 28 & 53 & 67 \\
\hline Prenatal care: Yes (ref.) & 4,253 & 48 & 88 & 19 & 50 & 56 \\
\hline No & 467 & 34 & 78 & 14 & 38 & 45 \\
\hline Exposure to media: not at all (TV) (ref.) & 6,825 & 53 & 88 & 24 & 51 & 64 \\
\hline Less than once a week & 285 & 58 & 88 & 31 & 54 & 66 \\
\hline At least once a week & 207 & 59 & 88 & 25 & 54 & 68 \\
\hline Every day & 268 & 61 & 93 & 35 & 52 & 69 \\
\hline Age cohort: $15-19$ years (ref.) & 397 & 36 & 88 & 14 & 43 & 43 \\
\hline$>19-24$ & 1,918 & 52 & 88 & 23 & 50 & 63 \\
\hline$>24-29$ & 2,027 & 55 & 89 & 26 & 51 & 65 \\
\hline$>29-34$ & 1,627 & 55 & 88 & 24 & 54 & 65 \\
\hline$>34-39$ & 1,011 & 56 & 87 & 26 & 54 & 67 \\
\hline$>39-44$ & 467 & 59 & 90 & 29 & 55 & 70 \\
\hline$>44-49$ & 144 & 64 & 90 & 31 & 53 & 78 \\
\hline Child's gender: Male (ref.) & 3,713 & 53 & 88 & 24 & 51 & 63 \\
\hline Female & 3,878 & 54 & 89 & 25 & 52 & 65 \\
\hline Woman's occupation: White collar job (ref.) & 183 & 66 & 96 & 34 & 62 & 74 \\
\hline Services/sales & 785 & 57 & 89 & 31 & 48 & 69 \\
\hline Agriculture & 5,623 & 54 & 89 & 24 & 53 & 64 \\
\hline Blue-collar job & 396 & 53 & 87 & 25 & 50 & 66 \\
\hline Partner's occupation: White-collar job (ref.) & 531 & 63 & 92 & 30 & 54 & 74 \\
\hline Services/sales & 950 & 55 & 87 & 23 & 53 & 64 \\
\hline Agriculture & 4,455 & 53 & 88 & 24 & 52 & 63 \\
\hline Blue-collar job & 1,342 & 52 & 89 & 23 & 50 & 64 \\
\hline Immunization card: No card (ref.) & 626 & 4 & 10 & 3 & 3 & 9 \\
\hline Had card and seen & 3,965 & 59 & 98 & 8 & 73 & 64 \\
\hline Had card but not seen & 2,120 & 56 & 92 & 49 & 35 & 75 \\
\hline No longer had card (missing) & 868 & 61 & 95 & 56 & 31 & 78 \\
\hline Total & 7,591 & 54 & 89 & 24 & 52 & 64 \\
\hline
\end{tabular}


professional prenatal care were fully immunized compared to $34 \%$ of children whose mothers never sought professional prenatal care (Table 2). Children whose mothers sought professional prenatal care increased the probability of being fully immunized, receiving DPT, polio vaccine, and measles vaccine by $9 \%(\mathrm{p}<0.01), 3 \%(\mathrm{p}<0.1), 6 \%(\mathrm{p}<0.05)$, and $6 \%$ $(\mathrm{p}<0.05)$ respectively compared to the counterparts whose mothers never sought professional prenatal care (Table 3).

Exposure to the media is also an important factor in our findings; $61 \%$ of children whose mothers watched TV daily were fully immunized compared to $53 \%$ of their counterparts who had no access at all. A similar pattern is found while considering the percentage of children who received a full dose of the individual vaccines. Children whose parents watched TV at least once a week increased the probability of being fully immunized by $9-15 \%(\mathrm{p}<0.05)$ compared to the counterparts whose parents had no access to media at all. Children whose parents watched TV less than once a week and daily increased the probability of receiving DPT by $9-10 \%$ $(\mathrm{p}<0.01)$ compared to the counterparts whose parents had no access to media at all.

Whereas there are minor differences across agegroups of mothers, the percentage of children fully immunized in totality and along the individual vaccines increased with the mother's age; $64 \%$ of children whose mothers were in $45-49$ years agecohort were fully immunized compared to $36 \%$ of children whose mothers were in the 15-19 years age-cohort (Table 2). A similar pattern was observed for the full dose of the individual vaccines. Children whose mothers were in 20-49 years age-cohort increased the probability of being fully immunized, receiving DPT, polio and measles vaccine by $9-30 \%$ $(\mathrm{p}<0.01), 5-23 \%(\mathrm{p}<0.05), 9-23 \%(\mathrm{p}<0.01)$, and 13$35 \%(\mathrm{p}<0.01)$ respectively (Table 3$)$.

Our findings reveal the importance of the type of occupation of parents of the child. Children whose mothers were in agriculture and blue-collar jobs reduced the probability of receiving the 3 doses of DPT by $8 \%(\mathrm{p}<0.05)$ and $5 \%(\mathrm{p}<0.1)$ respectively compared to the counterparts whose mothers had white-collar jobs. Similarly, children whose fathers were in agriculture and blue-collar jobs reduced the probability of being fully immunized and immunized against measles by $8-10 \%(\mathrm{p}<0.01)$ and $11-15 \%(\mathrm{p}<0.01)$ respectively compared to the counterparts whose fathers had white-collar jobs (Table 3). Findings in the bivariate analysis in Table
2 confirmed these regression results; $66 \%$ of children whose mothers had a white-collar job were fully immunized compared to 53\%, 54\%, and 57\% of children whose mothers were in blue-collar jobs, agriculture, and services respectively. A similar pattern was observed for partner's occupation and for individual vaccines.

Having an immunization card is shown to be important for full immunization. Children having immunization cards that were seen by the interviewer increased the probability of being fully immunized, receiving BCG, DPT, polio vaccine, and measles vaccine by $67 \%(\mathrm{p}<0.01), 72 \%(\mathrm{p}<0.01)$, $8 \%(\mathrm{p}<0.01), 76 \%(\mathrm{p}<0.01)$, and $64 \%(\mathrm{p}<0.01)$ respectively compared to the counterparts who had no card at all. Children having immunization card but not seen by the interviewer increased the probability of being fully immunized, receiving BCG, DPT, polio, and measles vaccine by $66 \%(\mathrm{p}<0.01)$, $21 \%(\mathrm{p}<0.01), 58 \%(\mathrm{p}<0.01), 52 \%(\mathrm{p}<0.01)$, and $64 \%(\mathrm{p}<0.01)$ respectively compared to the counterparts who had no card at all. Children who no longer had their cards increased the probability of being fully immunized, receiving BCG, DPT, polio, and measles vaccine by $60 \%(\mathrm{p}<0.01), 10 \%$ $(\mathrm{p}<0.01), 67 \%(\mathrm{p}<0.01), 46 \%(\mathrm{p}<0.01)$, and $53 \%$ $(\mathrm{p}<0.01)$ respectively compared to the counterparts who had no card at all (Table 3). It might be the case that some health centres, especially those in the rural areas, never issued immunization cards to children mainly due to shortage of supply. Findings in the bivariate analysis presented in Table 2 confirmed the regression findings. Only $4 \%$ of children who had no immunization card were fully immunized compared to $59 \%, 56 \%$, and $61 \%$ of children who had a card that was seen, a card which was not seen, and no longer had their cards respectively. However, the empirical and descriptive findings attached to children who had no immunization cards suffered a setback of a recall bias and, therefore, should be interpreted and considered for policy with caution.

\section{DISCUSSION}

This paper investigated the factors associated with childhood immunization status in Uganda. The finding that slightly over $50 \%$ of children were fully immunized is worrying in the face of very high infant and child mortality. This may probably be due to the ignorance of mothers or parents concerning the right dosage that a child is required to get. This is especially true for vaccines, like DPT and polio, that require three independent doses where some children may receive one dose or up to the second 
dose and do not complete the full course. Government effort is urgently needed to increase coverage of immunization by educating the population on the right doses of each vaccine and importance of completing it. There is a discrepancy between the level of vaccination coverage between DPT (24\%) and polio vaccine (52\%). These vaccines are often administered at the same time and, hence, their coverage rates are expected to be similar. According to the UDHS report, differences in coverage between DPT and polio result, in part, from stockouts of vaccines (2).

Maternal education has been highlighted as an important predictor of full childhood immunization and receiving individual vaccines. Literature attributes this to changes that accompany maternal education, such as changes in attitudes, traditions and beliefs, increased autonomy and control over household resources, which enhance healthcareseeking $(10,11,12,13)$. Our findings are in line with those from previous studies that articulated the importance of maternal education in the demand for childhood immunization $(3,4,8,10,14,15,16,17,18$, $19,20,21)$. Thus, the Universal Secondary Education Programme of the Government of Uganda is a commendable start that needs to be propelled to higher levels, with gender parity at the forefront.

We also found significant regional differences in the immunization coverage in Uganda. This may probably be attributed to the long distance of some regions from the vaccine distribution centres and from health facilities. Previous authors also found regional and locational disparities to be important $(3,4,14,19)$. Therefore, there is a need for the government effort to reach the disadvantaged regions and locations. The Government of Uganda should target rural areas by stocking the required vaccines in the community health centres or clinics. In addition, sensitization campaigns, especially targeting the uneducated, may go a long way in achieving this objective. In many of the cases, rural areas are disadvantaged due to poor road networks, especially during rainy seasons. Improving the transport facilities may also help solve the problem.

Mothers who sought prenatal care were associated with a higher likelihood of their children being fully immunized compared to the counterparts who did not seek prenatal care. This can be attributed to learning sessions that mothers are exposed to during prenatal care where the importance of timely immunization of the baby is emphasized. Our results are in agreement with the previous literature concerning the importance of prenatal care utilization $(8,20,29)$. Women should be sensitized to seek maternal healthcare services during pregnancy and childbirth as a way of having a continuous relationship with health workers even after childbirth.

Exposure to the media is significantly associated with childhood immunization. This can be attributed to the sensitization messages that parents receive through media to get their children immunized. The Government and other stakeholders should continuously advertise through media the importance of childhood immunization. In addition, government policy should ensure that various media channels fully penetrate the population as an effective way to disseminate the information.

We also found that the likelihood of childhood immunization increases with maternal age. This may be attributed to experience accumulated over time on the importance of immunization and also on the fatalities that have occurred to children due to lack of immunization. This finding is in line with that in the previous literature $(6,8)$. There is a need for more sensitization among young mothers on the importance of childhood immunization.

Mother's occupation and that of her partner are important in the attainment of full childhood immunization. Children whose parents held whitecollar jobs were more advantaged compared to those in agriculture, blue-collar jobs, and services/ sales. This may be attributed to the ease of accessibility to information that white-collar workers may have. It may also be due to accessibility to health facilities since the majority of white-collar workers are located in urban areas. Previous literature also found the type of occupation to be important in influencing childhood immunization (3). Government policy should be designed to target the disadvantaged, especially those in the agricultural sector by establishing village-level clinics with full stock of vaccines. It is not surprising that wealth status was not significant in influencing full childhood immunization since immunization is universal in Uganda. However, literature on other countries exposes the importance of the wealth status of the household $(3,5,16,22,23)$.

Having an immunization plan in the form of an immunization card was decisively important in our analysis. Mothers having a child immunization card can easily follow the immunization schedule and be able to attain timely immunization for their children. Previous researchers did find the impor- 


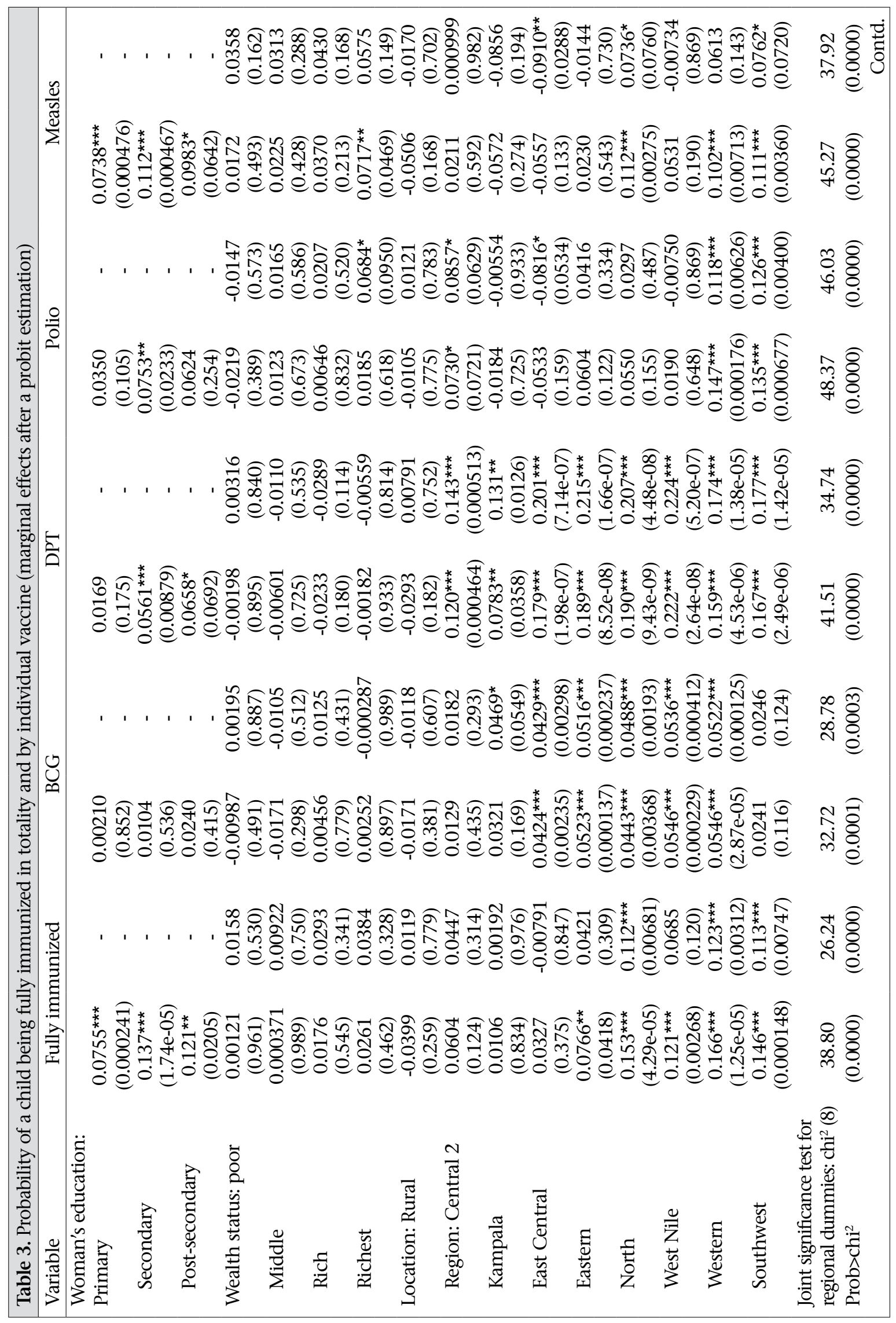




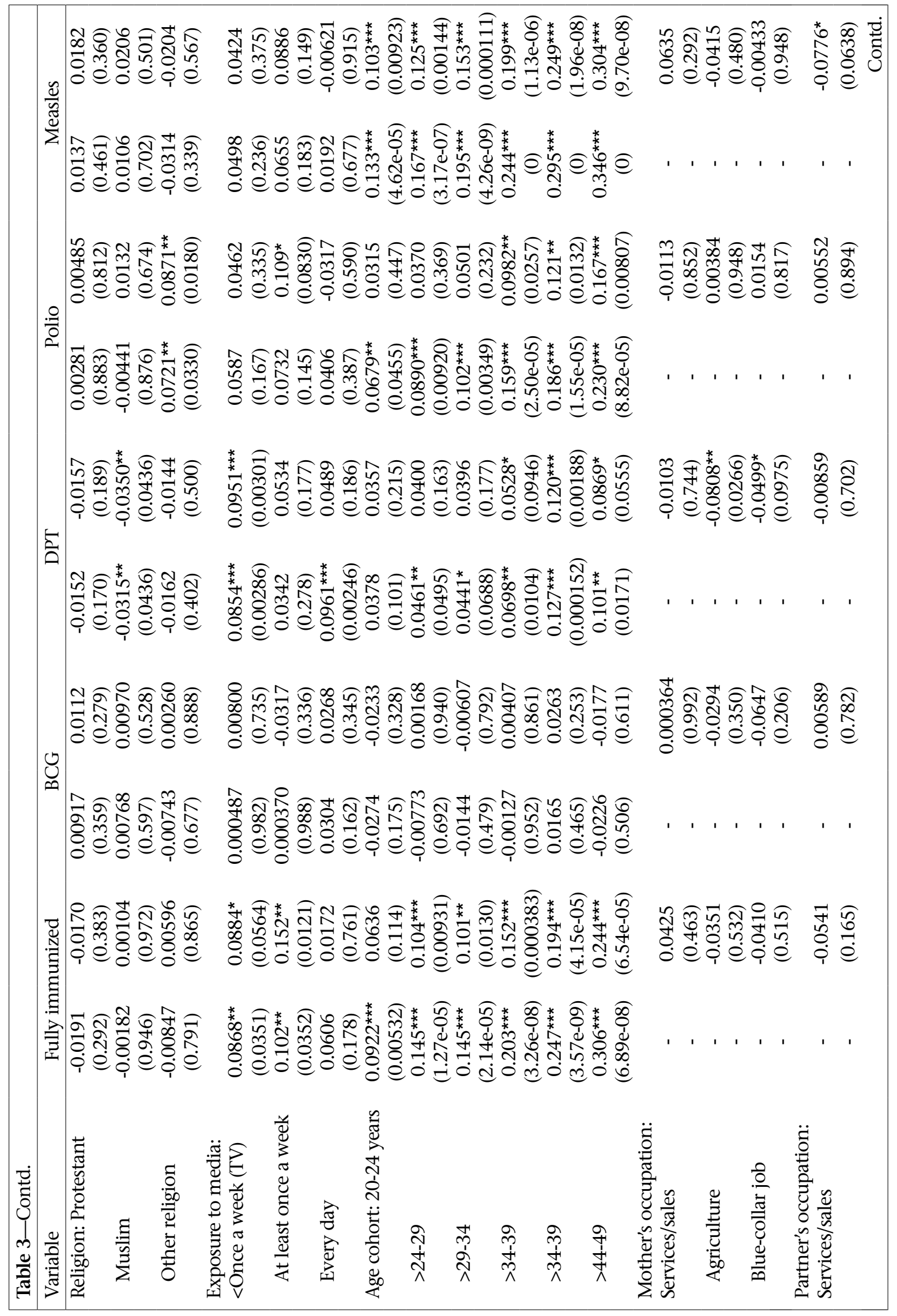




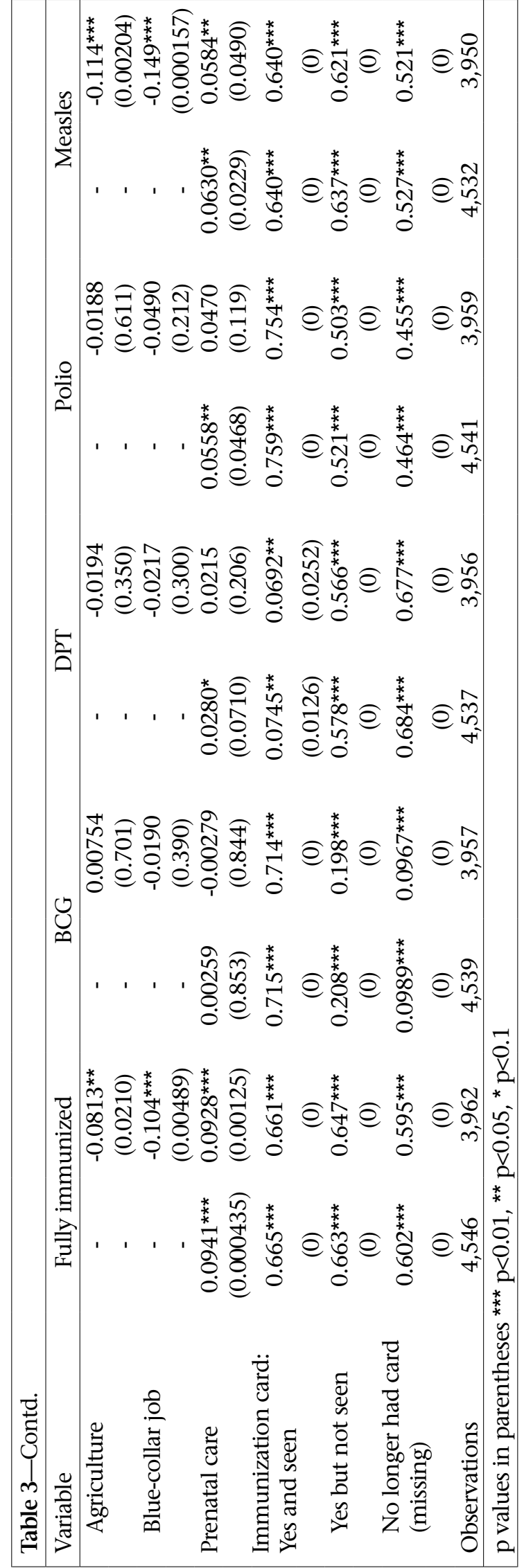

tance of having an immunization plan (16). Having a well-designed immunization card, with a clearly-labelled schedule, can go a long way in enhancing childhood immunization by reducing the forgetfulness of parents.

The greatest strength of our study is its use of data from a nationally-representative survey, which enhances generalization of results for the entire country. However, the primary source of limitation is the recall bias. Data were collected retrospectively for the past five years and, hence, mothers may not be in a position to recall very well all the events that took place during childhood immunization, especially where the card was missing. However, this bias did not occur in the case where the card was seen or available, and, luckily enough, this constituted the majority in our analysis.

\section{Conclusions}

This paper has provided insights into the factors associated with full childhood immunization in Uganda. This is expected to be of great importance to the policy-makers as the country trails with low childhood immunization, despite the universal immunization programme. Efforts are needed to enhance education, with gender parity at the forefront. There is also a need to strengthen the village outreach programme by establishing village-level clinics that are well-stocked with all vaccines to overcome regional disparities. Media outreach should also be increased among the population, and the Government can use this channel to disseminate a standard piece of information concerning the importance and doses of childhood immunization. Maternal healthcare services, such as prenatal care, should be enhanced so that there is a close contact between mothers, children, and health workers. Efforts are needed to create a comprehensive immunization plan labelled on an immunization card in a way that can easily be understood by the less educated. The future studies should find out which doses for an individual vaccine, say DPT, children require most-the first, second, or the third dose. This may help in the better understanding of the factors influencing full immunization.

\section{ACKNOWLEDGEMENTS}

The author acknowledges the Centre for Global Development (CGD) for offering a Visiting Fellowship that provided the time to write this article. Thanks are also due to IDRC for sponsoring the Fellowship and to Makerere University for granting 
leave. However, the views expressed in this article are those of the author and not of CGD.

\section{REFERENCES}

1. World Health Organization. State of world's vaccines and immunization. 3rd ed. Geneva: World Health Organization, 2009:1-169.

2. Uganda. Bureau of Statistics. Uganda Demographic and Health Survey 2006. Calverton, MD: Macro International, 2007. $467 \mathrm{p}$.

3. Bhandari P, Shrestha SS, Ghimire DJ. Sociocultural and geographical disparities in child immunization in Nepal. Asia Pac Popul J 2007;22:43-64.

4. Kiros GE, White MJ. Migration, community context, and child immunization in Ethiopia. Soc Sci Med 2004;59:2603-16.

5. Ndirangu J, Bärnighausen T, Tanser F, Tint K, Newell ML. Levels of childhood vaccination coverage and the impact of maternal HIV status on child vaccination status in rural KwaZulu-Natal, South Africa. Trop Med Int Health 2009;14:1383-93.

6. Breiman RF, Streatfield PK, Phelan M, Shifa N, Rashid M, Yunus M. Effect of infant immunisation on childhood mortality in rural Bangladesh: analysis of health and demographic surveillance data. Lancet 2004;364:2204-11.

7. Brenzel L, Wolfson LJ, Fox-Rushby J, Miller M, Halsey NA. Vaccine-preventable diseases. In: Jamison DT, Breman JG, Measham AR, Alleyne G, Claeson $\mathrm{M}$, Evans DB et al., editors. Disease control priorities in developing countries. 2nd ed. Washington, DC: World Bank, 2006:389-412.

8. Munshi R, Lee SH. Child immunization in Madhya Pradesh. Mumbai: International Institute for Population Sciences, 2000. 20 p. (National Family Health Survey Subject Reports no. 15)

9. United States Agency for International Development. MNPI: Maternal and Neonatal Program Effort Index: Policy Project. Washington, DC: United States Agency for International Development, 2006.

10. Streatfield K, Singarimbun M, Diamond I. Maternal education and child immunization. Demography 1990;27:447-55.

11. Cleland J. Maternal education and child survival: further evidence and explanations. In: Caldwell J, Findley S, Caldwell P, Santow G, Cosford W, Braid J et al., editors. What we know about health transition: the cultural, social and behavioural determinants of health. V. 1. Canberra: Australian National University, 1990:400-19.

12. Desai S, Alva S. Maternal education and child health: is there a strong causal relationship? Demography 1998;35:71-81.

13. Frost MB, Forste R, Haas DW. Maternal education and child nutritional status in Bolivia: finding the links. Soc Sci Med 2005;60:395-407.

14. Kidane T, Tekie M. Factors influencing child immunization coverage in a rural district of Ethiopia, 2000. Ethiop J Health Dev 2003;17:105-10.

15. Madise NJ, Matthews Z, Margetts B. Heterogeneity of child nutritional status between households: a comparison of six sub-Saharan African countries. Popul Stud 1999;53:331-43.

16. Waters HR, Dougherty L, Tegang SP, Tran N, Wiysonge CS, Long $\mathrm{K}$ et al. Coverage and costs of childhood immunizations in Cameroon. Bull World Health Organ 2004;82:668-75.

17. Anand S, Bärnighausen T. Health workers and vaccination coverage in developing countries: an econometric analysis. Lancet 2007;369:1277-85.

18. Ibnouf AH, Van den Borne HW, Maarse JM. Factors influencing immunisation coverage among children under five years of age in Khartoum State, Sudan. $S$ Afr Family Pract 2007;49:14.

19. Munthali AC. Determinants of vaccination coverage in Malawi: evidence from the demographic and health surveys. Malawi Med J 2007;19:79-82.

20. Bondy JN, Thind A, Koval JJ, Speechley KN. Identifying the determinants of childhood immunization in the Philippines. Vaccine 2009;27:169-75.

21. Nankabirwa V, Tylleskär T, Tumwine JK, Sommerfelt H; Promise-ebf Study Group. Maternal education is associated with vaccination status of infants less than 6 months in Eastern Uganda: a cohort study. BMC Pediatr 2010;10:92.

22. Defo BK. Areal and socioeconomic differentials in infant and child mortality in Cameroon. Soc Sci Med 1996;42:399-420.

23. Cui FQ Gofin R. Immunization coverage and its determinants in children aged 12-23 months in Gansu, China. Vaccine 2007;25:664-71.

24. Reichler MR, Darwish A, Stroh G, Stevenson J, Al Nasr MA, Oun SA et al. Cluster survey evaluation of coverage and risk factors for failure to be immunized during the 1995 National Immunization Days in Egypt. Int J Epidemiol 1998;27:1083-9.

25. Buor D. Analysing the primacy of distance in the utilization of health services in the Ahafo-Ano South district, Ghana. Int J Health Plann Manage 2003; 18:293-311.

26. Ndiritu M, Cowgill KD, Ismail A, Chiphatsi S, Kamau $\mathrm{T}$, Fegan $\mathrm{G}$ et al. Immunization coverage and risk 
factors for failure to immunize within the Expanded Programme on Immunization in Kenya after introduction of new Haemophilus influenzae type $\mathrm{b}$ and hepatitis b virus antigens. BMC Public Health 2006;6:132.

27. Müller I, Smith T, Mellor S, Rare L, Genton B. The effect of distance from home on attendance at a small rural health centre in Papua New Guinea. Int J Epidemiol 1998;27:878-84.

28. Guérin N. Assessing immunization coverage: how and why? Vaccine 1998;16(Suppl):S81-3.

29. Olusanya BO. Pattern and determinants of BCG immunisation delays in a sub-Saharan African community. Health Res Policy Syst 2010;8:1. 